\title{
PENGENALAN CITRA BOLA ROBOT BLUEHUMAN G8
}

\author{
Hadriansa $^{1)}$ dan Denis Prayogi ${ }^{2)}$ \\ ${ }^{1,2}$ Teknik Informatika, STMIK PPKIA Tarakanita Rahmawati \\ ${ }^{1,2}$ J1 Yos Sudarso RT 6 No 6, Tarakan, 77112 \\ E-mail : ansar@ppkia.ac.id ${ }^{1)}$, denis@ppkia.ac.id ${ }^{2}$
}

\begin{abstract}
ABSTRAK
Pengenalan citra merupakan suatu cara dari sebuah mesin komputer untuk mengenali objek atau benda yang memiliki pola dan bentuk. Pada bidang robotika, citra digunakan untuk mengenali sebuah objek benda dari bentuk maupun warna. Robot humanoid merupkan robot berbentuk manusia yang bisa dipertandingkan dengan permainan sepakbola, dimana robot harus mengejar bola kemudian menendang. Robot dapat melihat bola dengan proses citra digital dengan mendeteksi bentuk bola dan warna. Penelitian ini bertujuan untuk mendeteksi bola pada robot Humanoid dengan cara memanfaatkan sensor kamera pada robot, kemudian hasil citra yang direkam diproses menggunakan citra digital dengan model Hue, Saturation, Value (HSV). HSV merupakan suatu cara yang digunakan untuk mengetahui perbedaan intensitas dan kedalaman warna pada objek dengan area disekitarnya. Dengan menggunakan model HSV, citra bola di arena lapangan dapat terdeteksi oleh robot humanoid, sehingga dapat mendukung robot dalam mengejar dan menendang bola.
\end{abstract}

Kata Kunci: Citra Digital, Robot Humanoid, Bola, Sepak Bola.

\section{PENDAHULUAN}

Citra digital merupakan gambar dua dimensi yang bisa ditampilkan dilayar komputer sebagai himpunan pixel. Pengolahan citra dimanfaatkan untuk memanipulasi dan interprestasi digital dari citra dengan bantuan komputer.

Pemanfaatan citra digital untuk mendeteksi objek atau pola tertentu dapat diterapkan diberbagai bidang, salah satunya di bidang robotika. Di bidang ini biasanya dimanfaatakan agar robot dapat mendeteksi dan melihat benda yang ada di depannya.

Di Indonesia, robot yang cukup populer adalah robot Humanoid. Robot Humanoid merupakan robot berbentuk menyerupai manusia yang memiliki dua kaki, lengan, badan, kepala serta berjalan layaknya manusia pada umumnya. Robot Humanoid khususnya robot pemain bola dibangun dari serangkaian aktuator yang berupa servo dan bracket sebagai penyangga dan penyambung antar servo dan menghubungkannya satu sama lain (Rahmani dan Aprilianto, 2015).

Robot Humanoid setiap tahunnya dipertandingkan antar perguruan tinggi yang diadakan oleh Direktorat Jenderal Pembelajaran dan Kemahasiswaan, Kementrian Riset, Teknologi dan Pendidikan Tinggi dengan tema Kontes Robot Sepak Bola Indonesia atau biasa disebut dengan Humanoid Soccer.

Pertandingan robot ini mengikuti aturan sepak bola, di mana tim terdiri dari 3 robot yang dituntut untuk mencari keberadaan bola, mengejar, dan menendang kearah gawang lawan. Setiap tahunnya, terdapat rules atau tantangan robot yang dikeluarkan untuk menguji sejauh mana kemampuan robot dalam bermain bola. Pada tahun 2013, bola yang digunakan adalah bola berwarna orange dengan jenis bola tenis yang digunakan. Sehingga robot dituntut untuk mendeteksi objek bola berdasarkan warna. Namun sejak tahun 2017, bola yang digunakan tidak lagi berwarna orange atau bola tenis, akan tetapi bola yang benar-benar mengikuti standar FIFA (Federation of International Football Association) dengan ukuran 1 (satu) dan dominan berwarna putih. Hal ini menjadi tantangan baru karena warna bola dengan warna garis adalah sama, sehingga robot dituntut harus membedakan antara garis dan bola. Tuntutan rules inilah yang membuat robot memerlukan kemampuan pengolahan citra dan pengenalan pola yang baik agar dapat bertanding dan meraih hasil yang maksimal (Buku Panduan KRSBI Humanoid, 2017).

Berdasarkan penelitian yang telah dilakukan Khamdi dkk. (2017), pendeteksian objek bola dengan menggunakan metode Color Filtering HSV, menghasilkan kesimpulan bahwa metode tersebut dapat mendeteksi objek bola dengan diameter $6 \mathrm{~cm}$ dengan berbagai warna dengan jarak minimal 20 sampai $200 \mathrm{~cm}$. Akan tetapi objek bola merupakan bola bewarna polos Merah, Magenta, Hijau, Biru dan Kuning yang bukan merupakan bola standar FIFA ukuran 1 (satu) dengan dominan berwarna putih.

Pada penelitian ini, model HSV dimanfaatkan untuk mendeteksi objek bola yang digunakan pada pertandingan KRSBI divisi Humanoid. Bola berdimensi ukuran 1 (satu) standar FIFA dengan warna dominan hitam dan putih. Tantangan dari pendeteksian bola adalah bahwa robot harus bisa membedakan warna bola dengan warna garis putih yang ada di lapangan.

Pendeteksian bola memanfaatkan sebuah modul kamera yang dipasang pada raspberry pi. Untuk 
memproses citra bola, digunakan model HSV (hue, saturation, value) karena cara ini bisa membedakan objek dengan melihat perbedaan warna antara objek dengan area lapangan.

\section{RUANG LINGKUP}

Dalam penelitian ini permasalahan mencakup

1. Cakupan permasalahan.

Permasalahan pada robot pemain bola adalah bagaimana mencari dan mengetahui objek bola yang ada di depan robot. bola yang digunakan adalah bola kaki berwarna dominan putih. Hal ini mempunyai tingkat kesulitan di mana robot harus bisa mencari dan mendapatkan bola tapi tidak terganggu dengan warna garis putih pada lapangan.

2. Batasan-batasan penelitian.

Penelitian ini membatasi pada robot menggunakan Raspbery pi sebagai pemrosesan citra digital dalam hal ini menggunakan model HSV. Pendeteksian objek dengan memanfaatkan modul kamera yang dipasang pada raspberry pi.

Objek yang dideteksi adalah objek bola berwarna putih hitam dengan ukuran 1 (satu) yang diletakkan diarea lapangan bola.

3. Rencana hasil yang didapatkan.

Dari penelitian yang dilkakukan, robot dapat mendeteksi objek bola di lapangan dengan cara membedakan warna dan bentuk objek bola.

\section{BAHAN DAN METODE}

Pada penelitian ini, terdapat komponen komponen utama yang diperlukan dan metode untuk membantu proses penelitian. Adapun hal-hal yang diperlukan yaitu :

\subsection{Alat dan Bahan}

Dalam menunjang penelitian ini, terdapat beberapa komponen yang diperlukan, baik berupa komponen perangkat keras maupun komponen perangkat lunak. Adapun komponen-komponen yang diperlukan, yaitu :

1. Raspberry Pi

Raspberry pi yang digunakan adalah jenis raspberry pi Zero W (lihat gambar 1) yang merupakan komputer mini yang memiliki sistem operasi dan perangkat input dan output yang dapat dikendalikan oleh penggunannya menggunakan pemrograman tertentu seperti python. Raspberry ini memiliki keunggulan dari segi ukuran yang mini dibandingkan raspberry lainnya, sehingga bobotnya lebih ringan dan penempatan pada badan robot bisa menghemat tempat. Seri W memiliki arti bahwa raspberry pi dapat berkomunikasi dan terhubung menggunakan media transmisi nirkabel (wifi).

Zero $\mathrm{W}$ memiliki spesifikasi prosessor ARM single core dengan kecepatan maksimum $1 \mathrm{GHz}$, RAM sebesar 512 MB dan konsumsi daya kecil. Alasan ini yang membuat peneliti memilih alat ini sebagai pemrosesan data karena operasi bisa lebih cepat, ringan dan hemat energi.

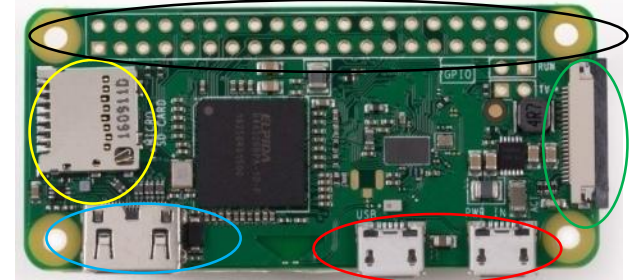

Gambar 1. Zero W

Seperti yang terlihat pada gambar 1, raspberry pi Zero W memiliki ukuran yang mini, di mana terdapat beberapa port yang digunakan untuk pengoperasiannya. Terdapat port power dan port input keyboard atau mouse dengan tipe USB (lingkaran merah). Terdapat juga port mini HDMI (High Defenition Multimedia Interfaces) untuk output layar ke monitor (lingkaran biru). Terdapat port khusus untuk modul kamera (lingkaran hijau), slot Micro SD untuk sistem operasi dan penyimpanan data (lingkaran kuning) dan port input output yang bisa digunakan untuk menghubungkan sensor dan perangkat keras lainnya (lingkaran hitam).

\section{Modul Kamera}

Modul kamera (lihat gambar 2) merupakan bagian penting dalam penelitian ini, dimana objek akan direkam oleh kamera khusus untuk raspberry pi. Modul kamera yang digunakan adalah V1.3 dengan resolusi maksimal $2594 \times 1944$.

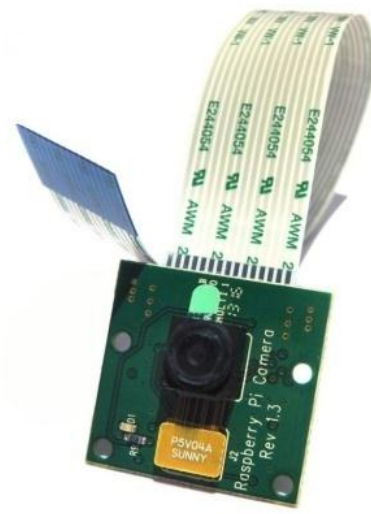

Gambar 2. Modul kamera Raspberry Pi

Modul kamera raspberry pi merupakan kamera yang khusus diperuntukkan dengan berbagai macam jenis raspberry pi. Keunggulan kamera ini adalah kecepatan dalam memproses data dikarenakan kompatibel dengan board raspberry pi.

\section{Robot Humanoid BlueHuman G8}

Robot Humanoid (lihat gambar 3) merupakan sebuah robot yang menyerupai manusia dan memiliki badan, kepala, lengan dan kaki. Robot berjalan dengan dua kaki dan menjaga keseimbangan agar tidak terjatuh(fariz, 2016).

BlueHuman G8 merupakan robot pemain bola generasi delapan dari tim Robot STMIK PPKIA 
Tarakanita Rahmawati yang mengikuti Kontes Robot Sepakbola Indonesia divisi Kid Size dengan dimensi tinggi minimal $40 \mathrm{~cm}$ hingga $60 \mathrm{~cm}$. Beberapa perbaikan dari generasi kedelapan ini salah satunya adalah kamera.

Kamera digunakan adalah kamera raspberry pi dimana hal ini dilakukan memperbaiki pendeteksian objek bola pada arena.

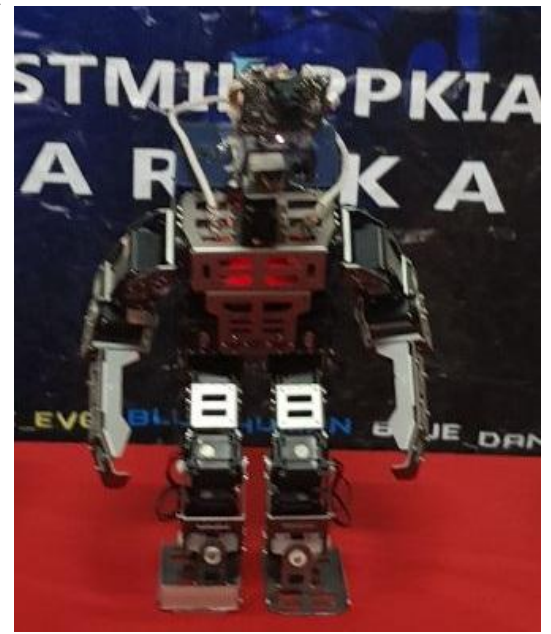

Gambar 3. Robot Humanoid G8

\subsection{Metode Penelitian}

Pada penelitian ini, terdapat beberapa langkahlangkah atau cara yang dilakukan sebagai penunjang penelitian seperti studi literatur, tinjauan pustaka dan sebagainya. Adapun beberapa teori pendukung penelitian sebagai berikut.

\subsubsection{Citra}

Secara harfiah, citra (image) adalah gambar pada bidang dwimatra (dua dimensi). Ditinjau dari sudut pandang matematis, citra merupakan fungsi menerus (continue) dari intensitas cahaya pada bidang dwimatra. Sumber cahaya menerangi objek, objek memantulkan kembali sebagian cahaya tersebut. pantulan cahaya ini ditangkap oleh alat-alat optik, misalnya pada mata manusia, kamera, pemindai (scanner) dan sebagainya, sehingga bayangan objek yang disebut citra tersebut terekam (fathi dkk., 2016).

\subsubsection{Model HSV}

Model HSV pertama kali diperkenalkan oleh A.R Smith pada tahun 1978. HSV dalam model RGB (Red, Green, Blue) tidak hanya mewakili warna, tetapi jua intensitas cahaya (lihat gambar 4). Model warna HSV transformasi non-linear dari ruang lingkup warna RGB berorientasi pada pengguna dan berdasarkan pada pengertian tint, shade dan tone (Charisfauzan, 2015).

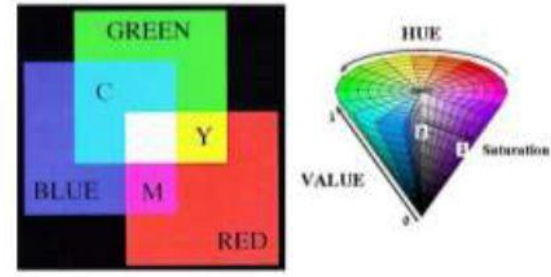

Gambar 4. sistem koordinat HSV

HSV memiliki tiga karakteristik pokok, yaitu Hue menyatakan warna sebenarnya seperti merah, kuning dan digunakan menentukan kemerahan (redness), kehijauan (greeness) dan sebagainya. Saturation sering juga disebut chroma yaitu kemurnian atau kekuatan warna. Sedangkan value merupakan kecerahan dari warna yang nilainya berkisar antara $0-100 \%$.

Untuk mendapatkan nilai dari model HSV, gambar atau video dalam RGB harus dikonversi terlebih dahulu menggunakan cara perhitungan formula(1-3) yaitu :

$$
\begin{gathered}
H=\tan \left(\frac{3(G-B)}{(R-G)+(R-B)}\right) \\
S=1-\left(\frac{\min (R, G, B)}{V}\right) \\
V=\frac{R+G+B}{3}
\end{gathered}
$$

Di mana :

$\mathrm{H}=$ hue

$\mathrm{S}=$ Saturation

$\mathrm{V}=$ Value

$\mathrm{R}=\mathrm{Red}$

$\mathrm{G}=$ Green

$\mathrm{B}=$ Blue

\subsubsection{OpenCV}

Open Computer Vision atau biasa disingkat OpenCV merupakan library yang banyak digunakan untuk memproses citra digital pada komputer. library ini dapat digunakan dan dikembangkan oleh Intel yang fokus untuk menyederhanakan programming terkait citra digital (Sidharta, 2017)

Salah satu fitur yang ada di OpenCV adalah penerapan model HSV untuk memproses gambar atau video melalui kamera dan diproses oleh komputer dalam penelitian ini menggunakan raspberry pi.

\subsubsection{Pengolahan Citra pada OpenCV}

beberapa morfologi dalam pengolahan citra antara lain :

1) smoothing sering juga disebut blurring dan sering kali digunakan pada operasi pemrosesan citra. Hal ini dilakukan untuk mengurangi noise dan camera artifact. Smoothing dapat menurunkan resolusi dari sebuah citra.

2) Image Morphology, openCV menyediakan kecepatan, antarmuka yang mudah digunakan untuk melakukan transformasi morfologi pada citra. Transformasi morfologi dasar disebut dilatasi dan 
erosi, mereka muncul dalam berbagai konteks seperti menghilangkan noise, mengisolasi unsur individu, dan menggabungkan elemen berbeda dalam citra. Morfologi juga dapat digunakan untuk menemukan benjolan intensitas atau lubang di gambar dan menemukan gradien gambar.

3) Opening dan closing adalah dua operasi utama pada dilasi dan erosi. Dalam kasus opening, dilakukan proses erosi kemudian dilasi. Sebalikanya closing kebalikan dari opening.

4) Thereshold mengambil keputusan dari piksel dalam gambar setelah dilakukannya proses-proses citra sebelumnya.

\section{Perancangan Perangkat Lunak}

Perancangan perangkat lunak dapat ditunjukkan pada gambar flowchart berikut ini :

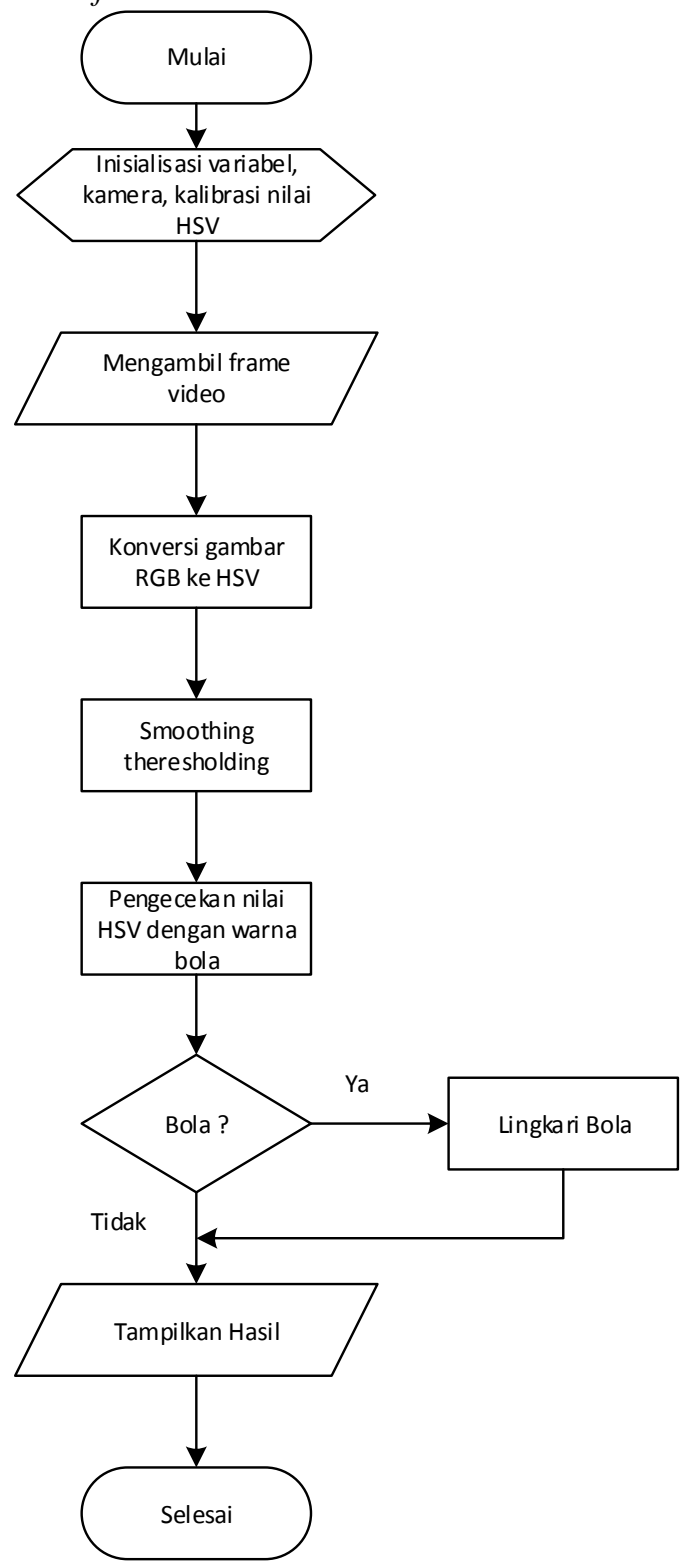

\section{Gambar 5. flowchart deteksi bola}

Dari gambar 5, dapat dilihat alur kerja dari pendeteksian bola. Pertama perangkat raspberry menyiapkan kamera untuk pengambilan objek dalam hal ini video. Kemudian, video yang direkam oleh kamera akan dilakukan proses konversi dari citra RGB menjadi citra HSV. Citra HSV akan menghasilkan video dalam bentuk kemerahan, kehijauan dengan kontras. Hasil dari HSV kemudian dilakukan proses theresholding atau perbaikan citra agar menjadi objek citra bilangan biner 0 dan 1. Theresholding ini juga dapat mengurangi noise atau gangguan yang ditangkap oleh kamera sehingga hasil dapat menjadi lebih baik.

Setelah proses theresholding, langkah selanjutnya adalah melakukan pengecekan nilai kalibrasi untuk bola yang berada dilapangan dengan kamera. Nilai yang dimaksud adalah nilai dari Hue, Saturation dan Value, dimana ketiga nilai ini dapat membentuk citra objek bola dari sekumpulan warna dari bilangan biner 0 dan 1 . Apabila kumpulan warna tersebut membentuk pola seperti lingkaran, maka objek tersebut akan dilingkari yang menandakan bola ditemukan.

\section{PEMBAHASAN}

Proses pengolahan citra yang dilakukan menggunakan raspberry pi dengan model HSV dapat dilihat seperti berikut.

\subsection{Proses pengambilan gambar}

Proses ini adalah pengambilan gambar secara langsung oleh kamera. Proses ini membentuk citra RGB dari video (lihat gambar 6).

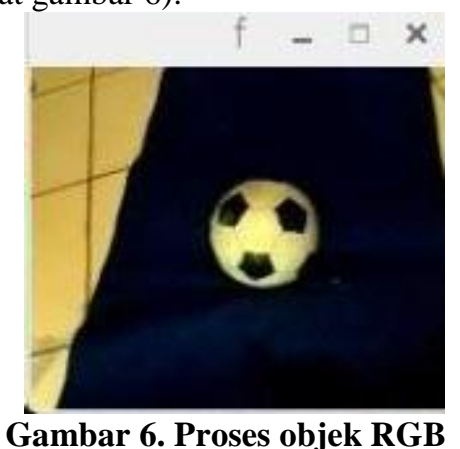

\subsection{Proses HSV}

Pada proses ini, objek RGB yang ditangkap akan dikonversi menjadi citra HSV.

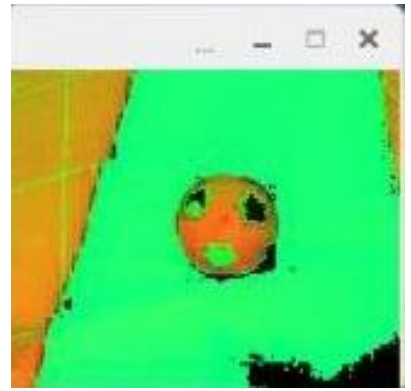




\section{Gambar 7 Proses RGB ke HSV}

Dari gambar 7, dapat terlihat perbedaan yang sangat kontras apabila citra telah dikonversi. Perbedaan warna yang kontras antara background dan objek inilah yang akan membentuk pola dari citra bola.

\subsection{Theresholding}

Theresholding merupakan proses pengembangan untuk menghasilkan citra biner, yaitu citra yang memiliki dua tingkat keabuan hitam dan putih (bustami, 2014).

Theresholding digunakan untuk memperbaiki citra digital pada objek yang dilihat, perbaikan yang dilakukan adalah mengurangi noise, bintik-bintik gambar, memperbaiki objek yang kosong, mem-blur gambar dan lain sebagainya (lihat gambar 8).

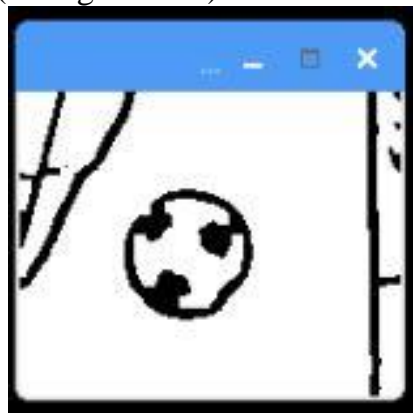

Gambar 8. Proses theresholding citra

\subsection{Kalibrasi Nilai HSV}

Proses ini adalah proses kalibrasi nilai-nilai dari Hue, Saturation dan value. Kalibrasi sangat penting dilakukan karena nilai-nilai yang dihasilkan akan sangat tergantung pada intensitas cahaya pada arena lapangan. Perubahan intensitas akan berpengaruh terhadap objek yang ditangkap oleh kamera.

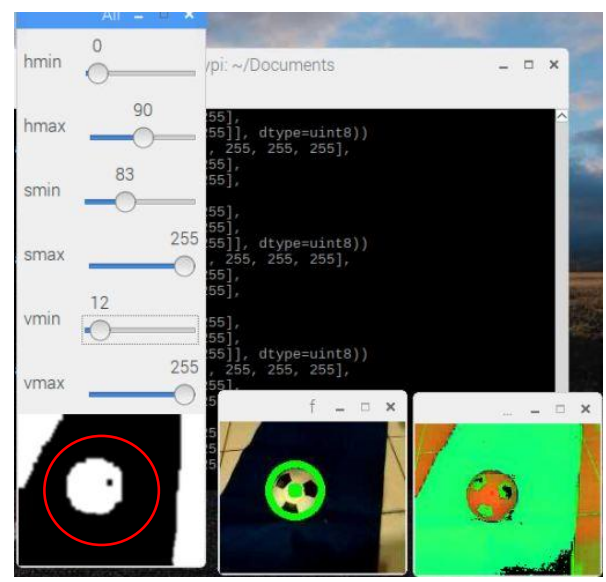

Gambar 9. kalibrasi HSV

Pada gambar 9, dapat dilihat proses kalibrasi yaitu mencari nilai yang pas untuk mengukur hue, saturation dan value. Nilai dari masing-masing terdiri dari min (nilai terkecil) dan max (nilai terbesar).

Nilai hue pada ruang warna memiliki nilai dengan range 0-179, Sedangkan Saturation dan Value berada direntang 0-255. Nilai-nilai ini kemudian diatur sehingga membentuk sekumpulan warna putih atau hitam. Pada penelitian ini pengaturan nilai pada masing-masing item dapat dilihat dari gambar 9 yaitu :

1. Hue berada pada nilai antara $0-179$

2. Saturation berada pada nilai $83-255$

3. Value berada pada nilai $12-255$

Rentang nilai yang telah diatur akan membentuk pola lingkaran dengan kumpulan warna putih seperti yang terlihat pada lingkaran merah. Pola inilah yang kemudian akan dilingkari seperti warna lingkaran hijau yang menandakan bahwa bola telah ditemukan.

\subsection{Hasil Uji Coba}

Berikut ini hasil percobaan yang telah dilakukan dari pendeteksian objek bola.

Tabel 1. Hasil Uji Coba

\begin{tabular}{|c|l|l|l|}
\hline $\begin{array}{c}\text { Percobaan } \\
\text { ke }\end{array}$ & \multicolumn{1}{|c|}{ Objek } & \multicolumn{1}{|c|}{ Tempat } & \multicolumn{1}{|c|}{ Hasil } \\
\hline 1 & Bola & Lapangan & Berhasil \\
\hline 2 & Bola & $\begin{array}{l}\text { Dekat garis } \\
\text { pinalti }\end{array}$ & Berhasil \\
\hline 3 & Bola & $\begin{array}{l}\text { Dekat garis } \\
\text { tengah }\end{array}$ & Gagal \\
\hline 4 & Bola & $\begin{array}{l}\text { Dekat Tiang } \\
\text { gawang }\end{array}$ & Berhasil \\
\hline 5 & Bola & $\begin{array}{l}\text { Diluar } \\
\text { lapangan } \\
\text { (background } \\
\text { non putih) }\end{array}$ & Berhasil \\
\hline 6 & Bola & $\begin{array}{l}\text { Diluar } \\
\text { lapangan } \\
\text { background } \\
\text { putih) }\end{array}$ & Gagal \\
\hline
\end{tabular}

Dari beberapa percobaan yang dilakukan pada tabel 1, terdapat beberapa keberhasilan dan kegagalan dalam mendeteksi objek bola. Objek bola terdeteksi dikarenakan perbedaan kontras antara objek dengan background lapangan. Sedangkan kegagalan deteksi dikarenakan warna objek dengan warna background hampir sama, sehingga ketika dilakukan theresholding terjadi kumpulan warna yang membentuk seperti lingkaran.

\section{KESIMPULAN}

Dari penelitian yang telah dilakukan, dapat disimpulkan bahwa pendeteksian objek bola menggunakan model HSV cukup akurat apabila terdapat perbedaan warna antara objek dengan background sehingga dapat membentuk suatu pola dalam hal ini lingkaran. Model HSV juga masih bisa mendeteksi posisi bola yang dekat dengan garis putih, sehingga dapat meminimalisir kesalahan pendeteksian.

Proses kalibrasi sangat diperlukan karena intensitas cahaya suatu ruangan atau area biasanya berbeda. Kesalahan dalam kalibrasi dapat menyebabkan robot gagal dalam pencarian objek bola. 
Kelemahan dari penggunaan model HSV ini adalah terjadinya kesalahan deteksi apabila objek dan background memiliki warna yang mirip.

\section{SARAN}

Dari penelitian yang telah dilakukan, adapun peneliti menyarankan agar objek penelitian dapat dikembangkan, diantaranya menggunakan metode yang dapat mendeteksi objek tanpa ketergantungan dengan warna. Sedangkan kamera sebaiknya menggunakan modul kamera raspberry dengan versi terbaru agar objek yang direkam dapat mengurangi gangguan seperti kurang cerah, kabur, blur serta memiliki resolusi yang tinggi.

\section{DAFTAR PUSTAKA}

Buku Panduan KRSBI Humanoid 2017 League Kid Size, 2017.

Bustami, M. Irwan., dkk, Mendeteksi Bentuk dan Warna Bola pada Humanoid Soccer Dengan Menggunakan Raspberry Pi. The $2^{\text {nd }}$ Indonesian Symposium On Robot Soccer Competition, 78-81, 2014, ISBN : 979-26-0273-9.

Charisfauzan. 2015. Ruang Warna Hue Saturation Value (HSV) Serta Proses Konversinya. http://www.charisfauzan.net/2015/01/ruang-warnahue-saturation-value-hsv.html. (diakses tanggal 14 Oktober 2018) .
Fariz, Razi Jamil, Kendali Keseimbangan Robot Humanoid. E-Proceeding of Engineering : Vol 3, 1421-1428, 2016.

Fathi, Zaki Muhammad., Arfianto Fahmi \& Unang Sunarya, Robot Pengenal dan Pencari Objek dengan Kamera Menggunakan Metode Transformasi Hough. Seminar Nasional Inovasi dan Aplikasi Teknologi Industri (SENIATI), 406-411, 2016, ISSN : 2085-4218.

Khamdi, Nur, Muhammad Susantok, and Piter Leopard. "Pendeteksian Objek Bola dengan Metode Color Filtering HSV pada Robot Soccer Humanoid." JURNAL NASIONAL TEKNIK ELEKTRO 6.2 (2017): 123-128.

Rahmani, Budi., Hugo Aprilianto, Model Kendali Multi Kontroler untuk Robot Humanoid dengan 19 Derajat Kebebasan. Konferensi Nasional Sistem \& Informatika, 2015.

Sidharta, Hanugra Aulia. 2017. Introduction To Open $C V$. http://binus.ac.id/malang/2017/10/introductionto-open-cv/. (diakses tanggal 17 Oktober 2018) 